\title{
Modeling the Interaction of Large and Small Industrial Entrepreneurship in Oil Refining
}

\author{
A.F. Andreev ${ }^{1}$ D.V. Bunkovsky ${ }^{2, *}$ \\ ${ }^{1}$ National University of Oil and Gas «Gubkin University», Moscow 119991, Russian Federation \\ ${ }^{2}$ East-Siberian Institute of the Ministry of Internal Affairs of Russia, Irkutsk 664074, Russian Federation \\ ${ }^{*}$ Corresponding author. Email: bdv611@yandex.ru
}

\begin{abstract}
The article describes an economic and mathematical multi-criteria model for the interaction of large and small (medium) industrial enterprises in oil refining and petrochemicals. The use of economic and mathematical modeling allows us to develop possible hypotheses in order to obtain additional information about the object of study, which is not available in the implementation of real business processes. Key criteria for optimizing the interaction of enterprises in the oil refining industry are given. Current conditions make it possible to bring priority criteria for optimizing the activities of enterprises in the oil refining industry to certain limit values. These include maximizing profits, minimizing reduced costs and maximizing value added. The constructed model gives a justification of the boundaries of the interests of large and small (medium) industrial enterprises in oil refining and petrochemicals, taking into account the criterion of maximizing profit. As an example, the article considers the interaction of industrial enterprises of various forms of utilization of by-products of oil refining and the development of petrochemical industries. A brief description of the spheres of interests of large and small (medium) industrial enterprises in oil refining and petrochemistry is given.
\end{abstract}

Keywords: industrial entrepreneurship, enterprise interaction, the complexity of the use of raw materials, oil

refining, small business

\section{INTRODUCTION}

Speaking about industrial entrepreneurship at the moment, we can safely say that its hidden potential exists in each of the sectors of the national economy [1-4]. It is possible to identify its level in the oil refining and petrochemical industries using a specially developed author's methodological approach. His assessment of the potential has a clear value of 5.52 points [5]. This corresponds to the interpretation of the "average" value of the potential over the interval [1: 10]. It is possible to apply unused potential (it is profitable to realize it) at small and medium industrial enterprises. Ultimately, this will lead to an increase in the efficiency of oil refining and petrochemical production, as well as the development of the complexity of processing valuable raw materials. Realization of the potential will allow generating additional tax revenues and creating additional jobs.

To effectively realize the identified and unused opportunities, you will need to organize and conduct additional business events. It will be necessary to simulate upcoming activities at the oil refinery complex in advance for the implementation of this project. Using economic and mathematical modeling of an object, it is necessary to select the most significant characteristics for consideration, while minimizing non-essential.

Using modeling, we will create possible hypotheses in order to obtain additional information about the object that is not available in the implementation of practical activities [6]. In addition, modeling complex structures, such as a crude oil refining complex, will significantly reduce the costs associated with the direct collection of information. The construction of multidimensional models of such objects and the formalization of the relations of their basic elements among themselves will create the possibility of quickly filling the remaining gaps in the existing knowledge about them and identifying new qualitative types of problems that were not immediately possible to foresee.

The value of virtual systems research lies in the fact that the data obtained during modeling are often superior to those that would become available in real research [7]. They are much wider and more accurate. Their nature is almost identical, but much less time and money is spent on their production [8]. All this proves the high efficiency of building models, and also allows you to visually evaluate how comprehensive and reliable the data are when comparing them with the results collected bit by bit in reality. The methodological justification of modeling assumes that the construction of models is based on the postulates of a system and optimization approaches.

\section{BACKGROUND}

The urgent problem is the closest interaction of large and small (medium) industrial enterprises in oil refining and petrochemicals [9-12]. To solve this problem, it is not 
enough to optimize the distribution of the volume of products produced by the refinery between its various consumers (groups of enterprises of the petrochemical and related industries). It is necessary to find the boundaries of interests between large and small (medium) businesses within the industry.

The ability to efficiently systematize and manage the activities of enterprises of various levels in the oil refining and petrochemical industries is realized using a multicriteria model, which includes the achievement of three basic conditions:

- $\quad$ maximum profit margin;

- $\quad$ highest value added;

- $\quad$ lowest total reduced costs.

This model makes it possible to describe a procedure that minimizes the existing discrepancies in supply and demand for products of the oil refinery complex, characteristic of the target market:

$$
\sum_{p=1}^{P} A_{p} C r_{p}-\sum_{p=1}^{P} \sum_{k=1}^{K} V_{k p} C_{k p}-\sum_{p=1}^{P} V_{p} C_{p} \rightarrow \min
$$

where:

$P$ - total number of product names derived from refining; $p$ - name of a specific product obtained from processing; $A_{p}$ - indicator of demand for the $p$-th type of product in the target markets, nat. units.;

$C r_{p}$ - the price of the $p$-th type of product is market, rubles / nat. units.;

$V_{k p}$ - output of the $p$-th type of product by the $k$-th competitor, nat. units.;

$C_{k p}$-price of the $p$-th type of product of the $k$-th competitor, $\mathrm{rub} /$ nat. units.;

$K$ - total number of competitors in target sales markets;

$V_{p}$ - total output of the $p$-th variety of product, nat. units;

$C_{p}-$ selling price per unit of the $p$-th type of product, rubles / nat. units.

The model requires the following restrictions:

- material balance of a crude oil refinery;

- $\quad$ structure of the main and secondary products.

The material balance of the oil refinery assumes that the total output of the enterprise for the entire manufactured range and the volume of feedstock for processing (i.e. crude oil) correspond to each other. As a result, we get:

$$
\sum_{p=1}^{P} V_{p j}=\sum_{t=1}^{T} V_{t}+\sum_{l=1}^{L} V_{l}
$$

where:

$T$ - total number of main distillation products;

$L-$ total number of by-products of oil distillation;

$t$ - name of the main type of product obtained after processing;

$l$ - name of the by-product type obtained after processing;

$V_{t}$ and $V_{l}$ - output volume of the $t$-th and $l$-th distillation product, nat. units.

$$
\sum_{p=1}^{P} V_{p j}=\sum_{t=1}^{T} d_{t} Q_{t}+\sum_{l=1}^{L} d_{l} Q_{l}
$$

where:

$Q_{t}$ and $Q_{l}$ - output volume of the main and secondary categories of oil products;

$d_{t}$ - share of $t$-th in the total output of basic processing products, share of units.;

$d_{l}$ - share of the $l$-th in the total output of by-products of processing, share of units.

$$
\sum_{p=1}^{P} V_{p j}=V_{o}-F_{o}
$$

where:

$V_{o}$ - refined oil volume, million tons;

$F_{o}$ - total production losses, million tons.

The structure of the main product can be described by the formula:

$$
\sum_{t=1}^{T} d_{t}=1
$$

And the structure of the by-product can be described by the formula:

$$
\sum_{l=1}^{L} d_{l}=1
$$

To create the model of the oil refinery under consideration, three local conditions for obtaining optimality must be fulfilled.

According to the first of them, the maximum possible profit is maximized, taking into account various options for the capacity utilization of the refinery (it depends on the investment options used to establish and develop production). To do this, the objective function, which maximize the absolute value of the amount of profit, is represented in the value of the calculated profit. The general view of it is reflected in this formula:

$$
\sum_{p=1}^{P}\left(\left(C_{p}-Z x_{p}-\alpha Z y_{p}\right) V_{p}-S_{p}\right) \rightarrow \min ,
$$

where:

$S_{p}$ - the amount of taxes paid in the production of $p$-th products, million rubles.;

$Z x_{p}$ - variable costs upon receipt of a unit of the $p$-th type of product, rub / nat. units;

$Z y_{p}$ - fixed costs upon receipt of a unit of $p$-th type product, $\mathrm{rub} /$ nat. units;

$\alpha$ - the ratio of unit constant costs to the changing volume of the final product in fractions of a unit.

where: 
$V_{p 1}$ and $V_{p 2}$ - output volume of the $p$-th product in physical terms before and after its change over the observed period, nat. units.

It is known that crude oil refining and cracking lead to various products. By economic and technological differences, they are classified as primary (target) and secondary (incidental). The first are low-boiling light fractions, in the volume of which large proportions of hydrogen and carbon are observed. Target products, as a rule, include gasoline, diesel fuel and kerosene. From an economic point of view, the physicochemical composition of these petroleum products is most valuable. By-products are actual waste from the processing of light fractions. By economic indicators, they are less profitable, although they find their application. These are gas fractions, bitumen, tar, sulfur, coke and technical oils. Given this separation, the function of the intended purpose for obtaining the maximum possible profit by business entities will look like this:

$$
\sum_{t=1}^{T} U_{t} V_{t}+\sum_{l=1}^{L} U_{l} V_{l} \rightarrow \max ,
$$

where:

$U_{t}$ and $U_{l}$ - profit margins remaining from the sale of units of the $t$-th and $l$-th products.

It is also necessary to keep in mind the existing dependence of economic efficiency on the structure of products produced, related to the volume and complexity of oil refining processes, as well as to the qualitative components of crude oil. Given the different profitability of products, any changes in the production and consumer structures can be a good impetus to improve financial and economic characteristics. If we take into account the structural component of each manufactured product, then the type of the target maximizing function to obtain the maximum possible profit changes:

$$
\sum_{t=1}^{T} U_{t} d_{t} Q_{t}+\sum_{l=1}^{L} U_{l} d_{l} Q_{l} \rightarrow \max
$$

The second condition maximizes the value of the resulting value added. It is determined by the difference between the total revenue from the sale of the product and the cost of acquiring the necessary raw materials. Given some correlation between this criterion and the previous one, they have different effects on processes related to management optimization in crude oil refineries.

Oil refining and petrochemicals are branches of the national economic complex, a distinctive feature of which are the relatively high costs of acquiring the necessary raw materials and materials, as well as paying for energy and depreciation. Therefore, they are considered not only material-intensive, but also energy-intensive, as well as capital-intensive. But the specific nature of the crude oil distillation process allows you to get the bulk of the fuel and energy resources necessary for technological purposes at the enterprise from refined raw materials.
The bulk of Russian oil refineries are firmly tied to vertically integrated oil corporations (vertically integrated oil companies), and also operate on tolling schemes. Their report on the production cost category does not contain a column of the cost of crude oil coming to them for processing. But a very significant division of costs at any refineries is allocated to mandatory depreciation. As a result, depreciation itself becomes the main component in the value-added indicator.

In this case, growing deductions for depreciation open up a number of new ways to increase the scientific and technological development of the entire complex under consideration. And the opportunity to bring the indicator to the maximum shows how much the scale of activity has expanded and the number of redistributions in oil refining has increased. Thus, we express it as an objective function that maximizes the total amount of added value, taking into account the range of oil products and the options for using the capacity of the refinery (depending on the investment projects proposed for the creation of production and its development). In general, the target function will receive the following form:

$$
\sum_{t=1}^{T}\left(C_{t}-G_{t}\right) d_{t} Q_{t}+\sum_{l=1}^{L}\left(C_{l}-G_{l}\right) d_{l} Q_{l} \rightarrow \max
$$

where:

$C_{t}$ - unit cost of the main $t$-th product obtained from oil, rub / nat units;

$C_{l}$ - unit cost of by-product of the $l$-th product obtained from oil, rub / nat units;

$G_{t}$ - material costs in the production of the $t$-th unit of production, rubles / nat. units;

$G_{l}$ - the cost of materials for the production of the $l$-th unit of production, rubles / nat. units.

And the following equality will limit this function:

$$
\sum_{t=1}^{T} G_{t}+\sum_{l=1}^{L} G_{l}=S_{o}-F r_{o}+M_{o}
$$

where:

$S_{o}$ - total cost for a given volume of raw materials $V_{o}$, rubles; $F r_{o}$ - processing losses, expressed in cost form, rubles;

$M_{o}-$ consumption of materials for the distillation of a given volume $V_{o}$, rubles.

The third condition is the lowest total reduced costs. It will be described by the objective function, which minimizes the reduced total costs of producing both the main and secondary types of products:

$$
\sum_{t=1}^{T} W_{t} d_{t} Q_{t}+\sum_{l=1}^{L} W_{l} d_{l} Q_{l} \rightarrow \min ,
$$

where:

$W_{t}$ - reduced costs for the production of a unit of production of the $t$-th type, rubles;

$W_{l}$-reduced costs for the production of a unit of production of the $l$-th type, rubles. 
To develop a concept for the oil refining and petrochemical industries, it should be borne in mind that with an increase in the quality component of the main product, the output of by-products increases. This creates the need to expand markets for their implementation or to increase the volume of forced disposal. In order to increase the consumption of by-products, the creation of a kind of supply chain that unites small and medium enterprises will be required.

Large business entities (refineries) have the choice of subsequent interaction or non-interaction with medium (small) business to solve the problems of recycling byproducts of their production. In order not to make mistakes in choosing an alternative, they will need to determine the criteria that reflect the benefits for large representatives of industrial entrepreneurship in these sectors. Most of Russia's oil refining business today is owned by vertically integrated oil companies operating within the global megaeconomic level. The scope of their interests does not include the development of the country's regions and the levels of economic or technical improvement of enterprises operating separately in their composition. The current specifics of entrepreneurship at this level in this area is based only on maintaining the level of marginal profitability of the main business processes. These companies use fixed assets, created mainly in the Soviet economy, and avoid investing in the expansion of these objects. Some investment projects are financed by them only according to the requirements of state authorities, or to comply with global technical regulations (for example, the acquisition of production lines for the production of fuel of European standard-3, 4, 5).

Also, the activity of a large sectoral business is stateforming (system-forming). If the high level of profitability in the oil refining industry decreases, it will freely withdraw capital from it and invest in another (for example, metallurgy). It will not be stopped by the risks of competitor interference and all kinds of barriers when entering new markets. In order to continue territorial development, stimulate these sectors and reduce the difficulty of using raw materials, the government should stimulate large businesses to support small and medium-sized enterprises in oil refining and petrochemicals. It is possible to create conditions for the interaction of subjects of large and small (medium) industrial entrepreneurship through the implementation of state socio-economic programs, environmental and innovative projects.

Given the above, the presence of large business in these areas is determined only by their profitability. Studying this phenomenon, you can apply the formula, which reflects the interests and degree of attractiveness for large and small (medium) entrepreneurs of projects related to the creation of industries that process the $l$-th product, obtained as a byproduct after oil refining:

$$
V_{c}=\frac{U_{r}+S_{c}}{C_{c}-P x_{c}-\beta P y_{c}}
$$

where:
$V_{c}$ - production volume of $c$-th product obtained from a byproduct of oil distillation, guaranteeing profit $U_{r}$, nat. units; $U_{r}$ - profit of a large business from the production of economically profitable products (currently satisfying it), million rubles;

$S_{c}$ - the amount of tax deductions from the sale of $c$-th production, million rubles;

$P x_{c}$ - the costs of obtaining a unit of $c$-th production are conditionally variable, rubles / nat. units;

$P y_{c}$ - the costs of obtaining a unit of $c$-th production are conditionally constant, rubles / nat. units.

$\beta$-ratio of fixed costs per unit of production to the changing volume of the final product in fractions of a unit.

where:

$$
\beta=\frac{V_{c 1}}{V_{c 2}}
$$

$V_{c 1}$ and $V_{c 2}$ - output volume of the $c$-th product in physical terms before and after its change over the observed period, nat. units A graphic reflection of the boundaries of intersecting interests between medium (small) and large industrial enterprises is shown in the figure 1.

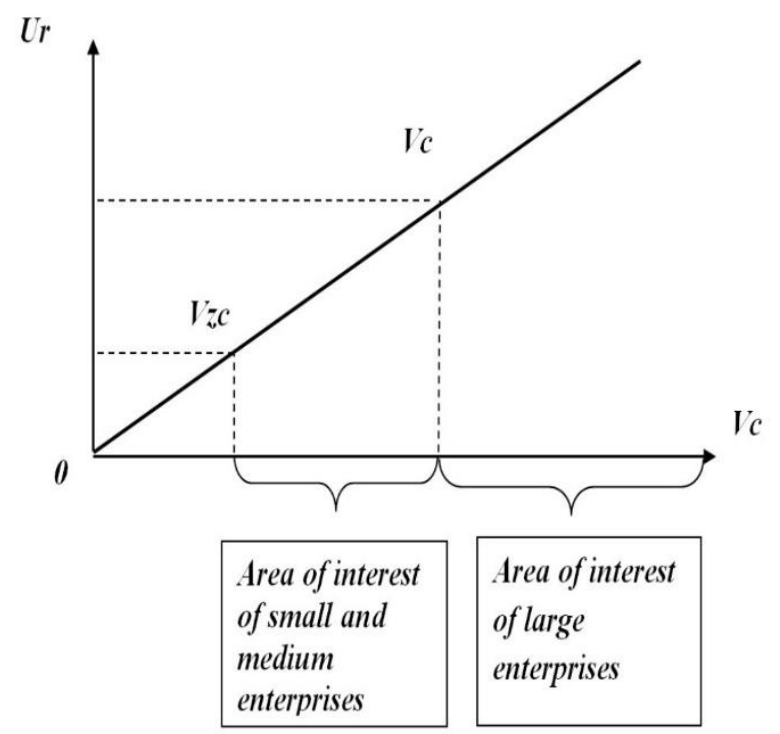

Figure 1 The boundaries of intersecting interests between medium (small) and large industrial enterprises

\section{CONCLUSION}

When the level of demand in the consumer market for $\mathrm{s}$ products obtained as a result of processing a by-product of the industry is less than the estimated $V_{c}$ and more than the break-even $V z_{c}$, it is in the interests of small and mediumsized businesses. At the same time, in order to get rid of the by-products of its production, it becomes convenient for a large business entity to develop interaction with these structures with high capabilities.

After the real level of demand and the volume of sales of products by small (medium) industrial enterprises becomes equal to $V_{c}$ or begins to exceed it, large enterprises will 
already be profitable to produce it, and this product will automatically be in their area of interest. As a result, representatives of a large business (in this case, an oil refining association) will try to absorb a small enterprise that processes their by-product or to finance the creation of a similar production facility with a capacity exceeding $V_{c}$.

\section{REFERENCES}

[1] A.A. Sozinova The Concept of Industrial Enterprises' Economic Development Amid the Global Financial and Economic Crisis, Lecture Notes in Networks and Systems, 2019, pp. 57.

[2] A. Polyakova, J. Nesterenko, E. Sverdlikova, Metainstitutions as a Product of Institutional Dynamics and Institutional Reformation, Postmodern openings, vol. 10 (2), 2019, pp. 137-154. DOI: 10.18662/po/76.

[3] E.A. Mosakova, Russia in the system of modern international labor migration, Russia and the modern world, vol. 2, 2017, pp. 113-121.

[4] N.V. Zhahov, V.S. Krivoshlykov, M.V. Shatokhin, Ways of modern agriculture in: specifics and state support, Proceedings of the 30th International Business Information Management Association Conference, IBIMA 2017 - Vision 2020: Sustainable Economic development, Innovation Management, and Global Growth 2017, 2017, pp. 3646-3652.

[5] D.V. Bunkovsky Assessment of the potential for the emergence and development of a small enterprise for the production of sulfur concrete, Bulletin of the Irkutsk State Economic Academy, vol. 4, 2011, pp. 120-122.

[6] O.V. Eliseeva, A.N. Ryabov, Methods of implementation and accounting of settlements with contractors, Basic research, vol. 11-4, 2013, pp. 715718.

[7] R.V. Fattakhov, M.M. Nizamutdinov, V.V. Oreshnikov, Tools for substantiating the parameters of the strategic development of the region on the basis of adaptive simulation, Region: Economics and Sociology, vol. 1, 2017, pp. 101-120.

[8] K.A. Kushnir, E.V. Gubanova, Research of development of enterprises of the defense-industrial complex in the Russian Federation, Chief mechanic, vol. 7, 2019, pp. 34-42.

[9] D.R. Peskova, J.V. Khodkovskaya, V.S. Charikov, et al., Development of business environment of oil and gas companies in digital economy, The European Proceedings of Social \& Behavioural Sciences. GCPMED 2018 International Scientific Conference "Global Challenges and Prospects of the Modern Economic Development", 2018, pp. 1205-1212. DOI: https://dx.doi.org/10.15405/epsbs.2019.03.122.

[10] E.F. Amirova, L.I. Petrova, E.V. Ziuzya, et al., Import substitution as an economic incentive mechanism for Russian commodity producers, International Journal of Civil Engineering and Technology, vol. 2, 2019, pp. 926-931.

[11] I.O. Botkin, T.N. Topoleva, Integration of an industrial enterprises: regional dimension, News of Science and Education, vol. 1, 2018, pp. 015-021.

[12] V. Kolmakov, A. Polyakova, Health sector performance under public-private partnership, European Proceedings of Social and Behavioural Sciences, vol. 26, 2017, pp. 436-443. DOI: 10.15405/epsbs.2017.07.02.56. 